\title{
Universiteit
}

Leiden

The Netherlands

\section{Trauma and dissociation in conversion disorder and chronic pelvic pain}

Spinhoven, P.; Roelofs, K.; Moene, F.; Kuyk, J.; Nijenhuis, E.M.; Hoogduin, C.A.L.; Dyck, R. van

\section{Citation}

Spinhoven, P., Roelofs, K., Moene, F., Kuyk, J., Nijenhuis, E. M., Hoogduin, C. A. L., \& Dyck, R. van. (2004). Trauma and dissociation in conversion disorder and chronic pelvic pain.

International Journal Of Psychiatry In Medicine, 34, 303-316. doi:10.2190/YDK2-C66W-CL6LN5TK

Version: $\quad$ Not Applicable (or Unknown)

License: $\quad$ Leiden University Non-exclusive license

Downloaded from: https://hdl.handle.net/1887/15198

Note: To cite this publication please use the final published version (if applicable). 


\title{
TRAUMA AND DISSOCIATION IN CONVERSION
} DISORDER AND CHRONIC PELVIC PAIN

\author{
PHILIP SPINHOVEN \\ KARIN ROELOFS \\ Leiden University \\ FRANNY MOENE \\ Organization for Mental Health "De Grote Rivieren," Dordrecht \\ JARL KUYK \\ Stichting Epilepsie Instellingen Nederland, Heemstede \\ ELLERT NIJENHUIS \\ General Psychiatric Hospital Drenthe, Assen \\ KEES HOOGDUIN \\ Radboud University Nijmegen \\ RICHARD VAN DYCK \\ Vrije Universiteit, Amsterdam
}

\section{ABSTRACT}

Objective: The purpose of this study was to: a) assess the link between sexual and/or physical abuse and dissociation in conversion disorder and chronic pelvic pain patients; and b) assess whether this effect is independent of level of general psychopathology. Method: This report examines data from four separate samples. Fifty-two patients with chronic pelvic pain, 61 patients with non-epileptic seizures, and two samples of patients (102 and 54) with predominantly motor or sensory types of conversion disorder were studied. Results: Using point-biserial correlations no compelling evidence for a consistent and positive association of sexual and/or physical abuse with dissociation was found. After statistically controlling for level of psychopathology using multiple regression analyses, in most of the cases the association of 
abuse with dissociation was no longer statistically significant. Only physical abuse predicted level of somatoform dissociation over and above level of psychopathology. Conclusion: In future clinical studies of dissociation in patients with conversion disorder and chronic pelvic pain more complex models may be needed with less exclusive reliance on historical antecedents such as childhood abuse and more emphasis on recent potentially traumatizing experiences or co-morbid psychiatric disorders.

(Int'l. J. Psychiatry in Medicine 2004;34:305-318)

Key Words: conversion disorder, dissociation, pelvic pain, non-epileptic seizures, somatoform disorder, trauma, psychopathology

\section{INTRODUCTION}

In clinical practice, it is widely assumed that early traumatic experiences may cause dissociative symptoms [1]. According to a rather elegant and simple trauma-genetic model, it is hypothesized that there is a robust and direct link between trauma and dissociation [2]. Trauma is thought to generate dissociation because dissociation is seen as an initially adaptive response to such experiences. In this view, dissociation implies the compartmentalization of traumatic experiences by which their impact is attenuated [3]. However, dissociation also manifests in disturbances of sensation, movement, and other bodily functions [4]. These disruptions - such as anesthesia, analgesia, sensory alterations, or loss of motor control - constitute the main symptom of conversion disorder and can be described as somatoform dissociation [5].

The main data in support of a trauma-genetic model of dissociation are derived from cross-sectional studies in which both self-reports of traumatic experiences and dissociation have been collected in clinical as well as non-clinical samples [6]. Moreover, the results of a limited amount of prospective and longitudinal studies also suggest that overwhelming events have the potential to induce dissociative phenomena [7, 8]. Empirical studies of the link between trauma and dissociation in patients with somatoform disorder, however, are relatively scarce. This is striking, given the fact that some bodily dysfunctions of patients with particular somatoform disorders can be regarded as manifestations of somatoform dissociation and as related to traumatic experiences [9]. Among the group of somatoform disorders, the few studies on trauma (in particular childhood, sexual abuse) and dissociation are mainly confined to conversion disorder and chronic pelvic pain disorder. The current article will elaborate upon our current knowledge of these two disorders.

As early as the end of the 19th century, Janet emphasized the association of childhood trauma with conversion disorder [10]. Non-epileptic seizures are the most frequently studied type of conversion disorder. Non-epileptic seizures are 
associated with both elevated scores for dissociation [11-15] and also a higher prevalence of sexual abuse ranging from $33 \%$ to $84 \%$ [11, 15-18]. More recently, elevated dissociation scores and prevalence rates of sexual and physical abuse in predominant motor and sensory types of conversion disorder have been reported $[19,20]$.

Sexual abuse may be a specific etiological factor in the development of chronic pelvic pain [21]. Various studies have reported high lifetime prevalence rates of reported sexual abuse among women with chronic pelvic pain, ranging from 50\% to $60 \%$ [21-23]. On the other hand, other studies [24, 25] report prevalence rates of sexual abuse not greatly exceeding the base rate in the general population estimated at about 25\% among women [26]. Moreover, Walker et al. [27] found that, in comparison to randomly selected women without a history of chronic pelvic pain, women with chronic pelvic pain reported elevated scores for psychological dissociation, while in the study of Nijenhuis et al. [24], the differences in psychological and somatoform dissociation were less pronounced.

Some authors, however, claim that a large component of dissociation scale scores does not specifically reflect dissociative psychopathology, but rather psychopathology in general [28]. In line with this claim, several studies have found that dissociation scores are highly correlated with scores for general psychopathology as measured, for example, with the Symptom Checklist-90 (SCL-90) [29]. These data question the specificity of the relationship of trauma with dissociation and suggest the possibility that the relation of trauma with dissociation can be accounted for (at least partly) by level of general psychopathology. Since many studies indicate that childhood abuse causes higher rates of psychiatric disorder in adults, it can be argued that higher dissociation scores constitute a marker for general distress rather than the direct and specific effects of childhood abuse. It has also been suggested that the link between trauma and dissociation may be indirect and mediated by general psychopathology [30]. It is interesting that most previous studies failed to study the link between trauma and dissociation while controlling for level of general psychopathology.

The data from four clinical studies in multiple patient groups with conversion disorder or chronic pelvic pain completed in the Netherlands during the last five years provided the data for this study [15, 19, 20, 24]. We performed additional analyses of the data from these studies in order to learn more about the association between reported trauma, general psychopathology, and dissociation.

\section{Aims of the Study}

The aims of the present study are: a) to investigate the association between sexual and/or physical abuse, psychological and somatoform dissociation in conversion disorder and chronic pelvic pain patients; and b) to assess whether this presumed relation between abuse and dissociation is independent of level of general psychopathology. 


\section{MATERIAL AND METHODS}

\section{Subjects}

Four separate samples were examined: patients with chronic pelvic pain, patients with non-epileptic seizures; and two samples of patients with predominantly motor or sensory types of conversion disorder.

\section{Chronic Pelvic Pain (CPP)}

This sample consisted of 52 consecutive female patients with chronic pelvic pain with a duration of at least six months [24]. Psychological factors were judged to have an important role in the onset, severity, exacerbation, or maintenance of the pain. Women were consecutively referred to the gynecology departments of two Academic Hospitals. Their mean age was 37.8 years $(S D=9.7)$.

\section{Non-Epileptic Seizures}

This sample consisted of 61 consecutive patients with a final diagnosis of non-epileptic seizure at the time of discharge from a tertiary center for the diagnosis and treatment of epilepsy. Non-epileptic seizures were defined as paroxysmal behavior patterns, mimicking epileptic seizures and initiated by psychological mechanisms. Twenty-seven of these patients have already been described in a previous study [15]. The sample was predominantly female (77\%) with a mean age of $31.5(S D=9.7)$.

\section{Conversion Disorder (CD)}

Two samples of patients with predominantly motor or sensory types of conversion disorder were included. The first sample of patients with conversion disorder consisted of 102 consecutive in- and outpatients referred to a psychiatric hospital or outpatient clinic specialized in the treatment of conversion disorder [19]. The sample was mostly female (74\%) with a mean age of 39.1 years $(S D=12.8)$. The second sample of conversion disorder patients consisted of 54 subsequent patients consecutively referred for either in- or outpatient treatment at the same institution [20]. Eighty-three percent of that sample was female and the mean age was $37.6(S D=11.9)$.

\section{Measures}

Dissociation

The Dissociative Experiences Scale (DES) [31] is a 28-item self-report questionnaire with scores ranging from " 0 " to " 100 ." Recently, it has been argued that "normal dissociation" (such as the capacity for imaginative absorption) exists on a 
continuum within the general population, but "pathological dissociation" does not [32]. In this view, pathological dissociation is a class variable, and a pathological dissociator is considered to be a member of a taxon. Based on eight items of the DES, it is possible to focus more explicitly on pathological dissociation by calculating a DES taxon score [32].

The Dissociation Questionnaire (DIS.Q) [33] is a 63-item self-report questionnaire with a 5-point Likert-type scale which apart from a total score measures the following four factors: identity confusion and fragmentation, loss of control, amnesia, and absorption.

The Somatoform Dissociation Questionnaire (SDQ-20) [34, 35] is a 20-item self-report questionnaire with a 5-point Likert-type scale which measures somatic manifestations of dissociation (such as kinesthetic anesthesia, motoric inhibitions, and dissociative loss of consciousness).

\section{Trauma}

The Structured Trauma Interview (STI) [36] assesses parental dysfunction, parental physical abuse and sexual abuse before the age of 16. Sexual abuse is defined as any pressured or forced sexual contact before age 16, ranging from fondling to penetration. Physical abuse is defined as severe parental aggression including recurrent and chronic forms of physical violence that could have hurt the child physically.

The Traumatic Experiences Checklist (TEC) [37] inquires about 29 types of potential trauma, including sexual and physical abuse. The questions contain short descriptions that are intended to define the events of concern.

The Short Trauma Questionnaire (STQ) of the Dissociation Questionnaire (DIS.Q) [38] asks subjects to indicate whether any or more of the following events took place: severe bodily injury, sexual abuse, emotional neglect; incest; war trauma; and other kinds of sexual, physical, or emotional abuse.

\section{Psychopathology}

The Symptom Checklist-90 (SCL-90) [39, 40] is a 90-item self-report questionnaire with a 5-point Likert-type scale, which yields a total score for level of general psychopathology.

The Hospital Anxiety and Depression Scale (HADS) [41, 42] is a 14-item self-report questionnaire with a 4-point Likert-type scale which gives a total score for affective complaints.

\section{Statistical Analysis}

Separate statistical analyses were performed for each of the four different samples. The association of self-reported sexual and physical abuse with measurements of dissociation was analyzed with point-biserial correlations. Semi-partial 
correlations coefficients were then calculated indicating the association of selfreports of trauma with measurements of dissociation after eliminating the variance that measurements of dissociation have in common with measurements of psychopathology. These semi-partial correlation coefficients were calculated using hierarchical multiple regression analysis with dissociation as the dependent variable and psychopathology as the independent variable forced into the equation in the first step and trauma in the second step of the equation. For the statistical analyses SPSS for Windows release 11.0 was used.

\section{RESULTS}

\section{Subject Characteristics}

Demographic data and level of psychopathology and dissociation in the various groups of patients with a somatoform disorder are presented in Table 1.

As seen in Table 1, the groups are quite comparable with respect to age and sex. However, patients with non-epileptic seizures are relatively younger than the other three groups of patients and the sample of patients with chronic pelvic pain consists of women only. According to norms for the SCL-90 [40] and HADS [42], the mean score for level of psychopathology of each group lies between the mean of a psychiatric outpatient population and the mean of a normal population.

Mean scores for psychological dissociation on the DIS.Q in patients with non-epileptic seizures and conversion disorder were higher than mean scores of normal controls $(M=1.5(S D=0.4))$ [33]. However, mean scores for psychological dissociation on the DES in patients with non-epileptic seizures and conversion disorder were quite comparable to the average DES score as found in the general population $(M=12(S D=11))$ in 1458 subjects from seven separate studies) [29]. Finally, mean scores for somatoform dissociation in all patient groups were elevated compared to patients with mixed psychiatric disorders (mainly anxiety disorder, depression and adjustment disorder) $(M=23(S D=4))$ [43].

The prevalence rates of self-reported sexual and/or physical abuse are presented in Table 2.

As seen in Table 2, all patient groups report base rates of sexual abuse (range: 23-37\%) and physical abuse (range: 20-29\%) which exceed the rates as found in the general population, but do not differ substantially from abuse rates in psychiatric controls as measured with the STQ [19], STI [36]. or TEC [37]. Interestingly, in one of the group of patients with conversion disorder both the STQ and STI were used and although it is assumed that self-reports may carry the risk of over-reporting, the abuse rates as obtained by the self-report STQ and the structured interview STI were almost identical. 
TRAUMA AND DISSOCIATION / 311

Table 1. Sample Characteristics

\begin{tabular}{|c|c|c|c|c|c|c|c|c|}
\hline \multirow[b]{3}{*}{ Variable } & \multicolumn{8}{|c|}{ Group } \\
\hline & \multicolumn{2}{|c|}{$\begin{array}{l}\text { Chronic } \\
\text { pelvic pain } \\
(N=52)\end{array}$} & \multicolumn{2}{|c|}{$\begin{array}{c}\text { Non-epileptic } \\
\text { seizures } \\
(N=61)\end{array}$} & \multicolumn{2}{|c|}{$\begin{array}{l}\text { Conversion } \\
\text { disorder } 1 \\
(N=102)\end{array}$} & \multicolumn{2}{|c|}{$\begin{array}{c}\text { Conversion } \\
\text { disorder } 2 \\
(N=54)\end{array}$} \\
\hline & $M$ & $S D$ & $M$ & $S D$ & $M$ & $S D$ & $M$ & $S D$ \\
\hline \multicolumn{9}{|l|}{ Demographics } \\
\hline $\begin{array}{l}\text { Gender } \\
\text { (\% female) }\end{array}$ & 100.0 & & 77.0 & & 74.5 & & 83.3 & \\
\hline Age & 38.8 & $(9.7)$ & 31.5 & $(9.7)$ & 39.1 & (12.8) & 37.7 & (11.9) \\
\hline \multicolumn{9}{|l|}{ Psychopathology } \\
\hline $\begin{array}{l}\text { SCL-90 } \\
\text { (range 90-450) }\end{array}$ & $(-)$ & & 159.2 & $(61.7)$ & 176.9 & $(62.0)$ & 201.2 & $(66.5)$ \\
\hline $\begin{array}{l}\text { HADS } \\
\text { (range 0-42) }\end{array}$ & 26.4 & (8.7) & $(-)$ & & $(-)$ & & $(-)$ & \\
\hline \multicolumn{9}{|l|}{ Dissociation } \\
\hline $\begin{array}{l}\text { DES } \\
\text { (range 0-100) }\end{array}$ & 8.6 & (12.0) & $(-)$ & & $(-)$ & & 12.0 & $(10.8)$ \\
\hline $\begin{array}{l}\text { DIS.Q } \\
\text { (range 1-5) }\end{array}$ & $(-)$ & $(1.7)$ & 0.5 & & 1.7 & $(0.6)$ & 1.9 & $(0.7)$ \\
\hline $\begin{array}{l}\text { SDQ } \\
\text { (range 20-100) }\end{array}$ & 25.7 & (9.3) & 28.8 & $(7.4)$ & $(-)$ & & 30.7 & (8.2) \\
\hline
\end{tabular}

SCL-90 = Symptom Checklist-90; HADS = Hospital Anxiety Depression Scale; DES = Dissociative Experiences Scale; DIS.Q = Dissociation Questionnaire; SDQ = Somatoform Dissociation Questionnaire

\section{Relationship of Traumatization with Dissociation}

The associations of physical abuse and sexual abuse and psychological and somatoform dissociation in the various groups of patients with somatoform disorders are summarized in Table 3.

As seen in Table 3, three out of eight correlations of sexual abuse with dissociation proved to be significant with coefficients ranging from medium to large in size (range: 26 to .49). More specifically, in patients with non-epileptic seizures and conversion disorder a significant association of self-reported sexual 
Table 2. Prevalence Rates of Self-Reported Sexual (SA) and Physical Abuse (PA)

\begin{tabular}{|c|c|c|c|c|c|c|c|c|}
\hline \multirow[b]{3}{*}{ Variable } & \multicolumn{8}{|c|}{ Group } \\
\hline & \multicolumn{2}{|c|}{$\begin{array}{c}\text { Chronic } \\
\text { pelvic pain } \\
(N=52)\end{array}$} & \multicolumn{2}{|c|}{$\begin{array}{l}\text { Non-epileptic } \\
\text { seizures } \\
(N=61)\end{array}$} & \multicolumn{2}{|c|}{$\begin{array}{l}\text { Conversion } \\
\text { disorder } 1 \\
(N=102)\end{array}$} & \multicolumn{2}{|c|}{$\begin{array}{c}\text { Conversion } \\
\text { disorder } 2 \\
(N=54)\end{array}$} \\
\hline & SA & PA & SA & PA & SA & PA & SA & PA \\
\hline TEC & 32.7 & 28.8 & 29.5 & 25.9 & $(-)$ & $(-)$ & $(-)$ & $(-)$ \\
\hline STQ & $(-)$ & $(-)$ & $(-)$ & $(-)$ & 23.5 & 19.6 & 37.0 & 25.9 \\
\hline STI & $(-)$ & $(-)$ & $(-)$ & $(-)$ & $(-)$ & $(-)$ & 37.0 & 27.8 \\
\hline
\end{tabular}

TEC = Traumatic Experiences Checklist, STQ $=$ Short Trauma Questionnaire, STI = Structured Trauma Interview

abuse with SDQ scores for somatoform dissociation was found, while in one of the samples of patients with conversion disorder also a positive association between self-reported sexual abuse with DIS.Q scores for psychological dissociation was observed. With respect to the association of physical abuse with level of dissociation, four out of the eight associations analyzed were statistically significant. A positive association of self-reported physical abuse with SDQ-scores for somatoform dissociation in patients with chronic pelvic pain, non-epileptic seizures and conversion disorder was found, as well as a positive association of physical abuse with scores for psychological dissociation in patients with non-epileptic seizures.

In patients with non-epileptic seizures and conversion disorder, DES taxon and DES total scores were highly correlated $(r=.94 ; r=.93)$. Moreover, in comparison to DES total scores, DES taxon scores were significantly lower $(t(51)=6.75$, $p<.001 ; t(53)=5.63, p<.001)$ in patients with chronic pelvic pain $(M=4.9$; $S D=11.6)$ and conversion disorder $(M=8.6 ; S D=11.8)$. None of the correlations between sexual and physical abuse and DES taxon scores was statistically significant (correlations in patients with chronic pelvic pain respectively .18 and .26 and in patients with conversion disorder respectively .05 and .22).

\section{General Psychopathology as a Mediating Factor}

Next, in order to investigate whether the association of trauma with dissociation is indirect and mediated by level of general psychopathology, semi-partial correlations were calculated. In this context, semi-partial correlations are the correlations of self-reports of trauma with measurements of dissociation after the effects 
Table 3. Correlations and Semi-Partial Correlations (in Parentheses) between Self-Reported Sexual and Physical Abuse and Measurements of Psychological and Somatoform Dissociation

\begin{tabular}{|c|c|c|c|c|c|c|c|c|}
\hline \multirow[b]{3}{*}{ Variable } & \multicolumn{8}{|c|}{ Group } \\
\hline & \multicolumn{2}{|c|}{$\begin{array}{l}\text { Chronic } \\
\text { pelvic pain } \\
(N=52)\end{array}$} & \multicolumn{2}{|c|}{$\begin{array}{l}\text { Pseudo epileptic } \\
\text { seizures } \\
(N=27)\end{array}$} & \multicolumn{2}{|c|}{$\begin{array}{l}\text { Conversion } \\
\text { disorder } 1 \\
(N=102)\end{array}$} & \multicolumn{2}{|c|}{$\begin{array}{c}\text { Conversion } \\
\text { disorder } 2 \\
(N=54)\end{array}$} \\
\hline & DES & $\mathrm{SDQ}$ & DIS.Q & SDQ & DIS.Q & DES & DIS.Q & $\mathrm{SDQ}$ \\
\hline $\begin{array}{l}\text { Sexual } \\
\text { abuse }\end{array}$ & $\begin{array}{c}.26 \\
(.16)\end{array}$ & $\begin{array}{l}.32^{\star} \\
(.21)\end{array}$ & $\begin{array}{c}.24 \\
(-.07)\end{array}$ & $\begin{array}{l}.37^{\star *} \\
(.15)\end{array}$ & $\begin{array}{r}.26^{*} \\
(.13)\end{array}$ & $\begin{array}{c}.04 \\
(-.07)\end{array}$ & $\begin{array}{c}.16 \\
(.13)\end{array}$ & $\begin{array}{l}-.08 \\
(-.10)\end{array}$ \\
\hline $\begin{array}{l}\text { Physical } \\
\text { abuse }\end{array}$ & $\begin{array}{c}.25 \\
(.21)\end{array}$ & $\begin{array}{c}.35^{\star} \\
\left(.30^{\star}\right)\end{array}$ & $\begin{array}{r}.28^{\star} \\
(-.04)\end{array}$ & $\begin{array}{l}.27^{*} \\
(.04)\end{array}$ & $\begin{array}{c}.10 \\
(.08)\end{array}$ & $\begin{array}{c}.11 \\
(.13)\end{array}$ & $\begin{array}{c}.08 \\
(.11)\end{array}$ & $\begin{array}{c}.26^{\star} \\
\left(.27^{\star}\right)\end{array}$ \\
\hline
\end{tabular}

DES = Dissociative Experiences Scale; DIS.Q = Dissociation Questionnaire; SDQ = Somatoform Dissociation Questionnaire-20; ${ }^{*} p<.05$; ${ }^{* *} p<.01$; semi-partial correlations in parentheses refer to the association of trauma with dissociation scores after eliminating the common variance between dissociation and psychopathology scores.

of psychopathology on dissociation have been removed. These semi-partial correlations are presented in parentheses in Table 3. Only two of the seven statistically significant uncontrolled correlations of trauma with dissociation remained significant. A positive association between self-reported physical abuse and SDQ-20 scores for somatoform dissociation in patients with chronic pelvic pain and conversion disorder was found.

\section{DISCUSSION}

On the basis of a simple trauma-genetic model it could be hypothesized that in the four studies in chronic pelvic pain and conversion disorder patients all the 16 investigated associations between sexual and physical abuse and psychological and somatoform dissociation should have been statistically significant and positive. The results, however, showed that only seven out of the 16 associations were statistically significant and positive. In addition, no evidence for a significant association of abuse with psychological aspects of dissociation was found by focusing on pathological aspects of dissociation as measured by the DES-taxon. After statistically controlling for level of psychopathology, it was found that only two of these seven associations remained significant. These results show that the association of trauma with dissociation is at least inconsistent and can partly be accounted for by level of general psychopathology. 
Only in the group of patients with chronic pelvic pain and conversion disorder did physical abuse predict level of somatoform dissociation over and above level of psychopathology. These associations suggest a direct link of physical abuse with somatoform aspects of dissociation independent of level of general psychopathology in two of the three groups in which somatoform aspects of dissociation were measured. These results are consistent with the results of a previous study that found that the SDQ-20 measures a unique construct-somatoform dissociation - which is strongly associated with but not identical to psychological dissociation and general psychopathology [43].

In interpreting these results, it is important to realize the possibilities and limitations of the present study design. Using a within-group analysis, it is possible to study the association of self-reported trauma with level of dissociation in patient groups with somatoform disorders. Using clinical samples, however, may introduce substantial bias and it is not warranted to infer causal pathways on the basis of cross-sectional correlations. For example, it cannot be excluded that persons with a history of childhood traumatization and high levels of psychopathology are more likely to seek treatment than those with similar levels of psychopathology without trauma, giving rise to an apparent but spurious relationship. The results of studies in random population samples may give more reliable evidence about possible pathways. Using such an approach, it has been observed that a number of chronic physical conditions are found more often in women who reported different types of sexual and physical abuse, both in childhood and in adult life. However, increased rates of dissociation appeared important only in chronic fatigue and headache, suggesting that dissociation is not part of the pathway between abuse experiences and other later physical health problems [44].

The inconclusive findings on the prediction of dissociation in the present study may be due to weaknesses in the abuse measures and dissociation measures used. Our results should affect choice, conceptualization, and operationalization of both criterion and predictor variables in future studies. The clinical validity of the DES, for example, has been questioned. However, the present study which focused more explicitly on pathological dissociation [32] yielded results almost identical as when focusing on psychological dissocation in general. The predictor variables are also problematic. The reporting of abuse was retrospective and no independent corroboration of the alleged traumatic events was obtained. Because autobiographical memories are reconstructive and open to postevent influences, the validity of the abuse reports cannot be ensured [45]. In addition to this crucial aspect of the possible unreliability of retrospective self-reports of traumatic childhood events, also the question of whether the remembered events indeed qualify as traumatic events capable of producing elevated levels of dissociation is often not adequately addressed. Incorporating details about age, duration, setting, and especially subjective distress during traumatization seem important in order to refine our measures. 
In the light of the present results, interpreting childhood sexual and physical abuse as a necessary or sufficient condition for the development of dissociative symptoms in chronic pelvic pain and conversion disorder seems superficial and naïve. Even though a small to moderate portion of the variance in dissociation scores can be explained by special forms of abuse, this leaves most of the variance in dissociation unaccounted for. Besides fantasy proneness [6], several other candidates are mentioned in the literature, such as the emotional climate in the family of origin [46], recent traumatic experiences [47], psychiatric co-morbidity [30], or cumulative, life-time traumatization [20]. In future studies it seems advisable to use a multivariate approach to the analysis of correlates of dissociation as has been useful in patients with gastrointestinal complaints [48] and therefore abandon the study of the isolated relation of trauma with dissociation. More complex models may be needed, with less emphasis on historical antecedents and more emphasis on current causative and/or maintaining factors.

In conclusion, no compelling evidence for a positive and substantial association of sexual and physical abuse with level of psychological or somatoform dissociation in patients with chronic pelvic pain and conversion disorder was found. The association of trauma with dissociation seems to be partly mediated by level of general psychopathology. In future clinical studies of dissociation in patients with chronic pelvic pain or conversion disorder, more complex models may be needed with less exclusive emphasis on historical antecedents such as childhood abuse and more emphasis on current causative and/or maintaining factors such as recent potentially traumatizing experiences, co-morbid psychiatric disorders, or cumulative, life-time traumatization.

\section{REFERENCES}

1. Chu JA, Dill DL. Dissociative symptoms in relation to childhood physical and sexual abuse. American Journal of Psychiatry 1990;147:887-892.

2. Frankel FH. Dissociation: The clinical realities. American Journal of Psychiatry 1996;153(Festschrift Supplement):64-70.

3. Spiegel D, Cardena E. Disintegrated experience: The dissociative disorders revisited. Journal of Abnormal Psychology 1991;100:366-378.

4. Briquet P. Traité clinique et thérapeutique de l'hystérie (2 vols.). [Clinical and therapeutic treatise of hysteria]. Paris: J.-P. Baillière \& Fils, 1859.

5. Nijenhuis ERS, Spinhoven P, Vanderlinden J, Van Dyck R, Van der Hart O. Somatoform dissociative reactions as related to animal defensive reactions, to predatory threat and injury. Journal of Abnormal Psychology 1998;107:63-73.

6. Merckelbach H, Muris P. The causal link between self-reported trauma and dissociation: A critical review. Behaviour Research and Therapy 2001;39:245-254.

7. Macfie J, Cicchetti D, Toth SL. The development of dissociation in maltreated preschool-aged children. Development and Psychopathology 2001;13:233-254. 
8. Ogawa JR, Sroufe LA, Weinfield NS, Carlson EA, Egeland B. Development and the fragmented self: Longitudinal study of dissociative symptomatology in a nonclinical sample. Development and Psychopathology 1997;9:855-879.

9. Kihlstrom JF. Dissociative and conversion disorders. In Stein DJ, Young JE, editors. Cognitive science and clinical disorders. San Diego: Academic Press, 1992: 247-270.

10. Janet P. The major symptoms of hysteria. London: Macmillan, 1907.

11. Bowman ES. Etiology and clinical course of pseudoseizures. Relationship to trauma, depression and dissociation. Psychosomatics 1993;34:333-342.

12. Alper K, Devinsky O, Perrine K, Luciano D, Vasquez B, Pacia S et al. Dissociation in epilepsy and conversion nonepileptic seizures. Epilepsia 1997;38: 991-997.

13. Litwin R, Cardena E. Demographic and seizure variables, but not hypnotizability or dissociation, differentiated psychogenic from organic seizures. Journal of Trauma and Dissociation 2000;1:99-122.

14. Prueter C, Schultz-Venrath U, Rimpau W. Dissociative and associated psychopathological symptoms in patients with epilepsy, pseudoseizures, and both seizure forms. Epilepsia 2002;43:188-192.

15. Kuyk J, Spinhoven P, van Emde Boas W, Van Dyck R. Dissociation in temporal lobe epilepsy and pseudo-epileptic seizure patients. Journal of Nervous and Mental Disease 1999;187:713-720.

16. Betts T, Boden S. Diagnosis, management and prognosis of a group of 128 patients with non-epileptic attack disorders. Part II. Previous childhood sexual abuse in the aetiology of these disorders. Seizure 1992;1:27-32.

17. Alper K, Devinsky O, Perrine K, Vasquez B, Luciano D. Nonepileptic seizures and childhood sexual and physical abuse. Neurology 1993;43:1950-1953.

18. Bowman ES, Markland ON. Psychodynamic and psychiatric diagnoses of pseudoseizures subjects. American Journal of Psychiatry 1996;153:57-63.

19. Moene FC, Spinhoven P, Hoogduin CAL, Sandijck P, Roelofs K. Hypnotizability, dissociation, and trauma in patients with a conversion disorder: An exploratory study. Clinical Psychology and Psychotherapy 2001;8:400-410.

20. Roelofs K, Keijsers GPJ, Hoogduin CAL, Näring GWB, Moene FC. Childhood abuse in patients with conversion disorder. American Journal of Psychiatry 2002; 159:1908-1913.

21. Walling EA, Reiter RC, O'Hara MW, Milburn AK, Lilly G, Vincent SD. Abuse history and chronic pain in women. I. Prevalence of sexual and physical abuse. Obstetrics \& Gynecology 1994;84:193-199.

22. Badura AS, Reiter RC, Altmaier EM, Rhomberg A, Elas D. Dissociation, somatization, substance abuse, and coping in women with chronic pelvic pain. Obstetrics \& Gynecology 1997;90:405-410.

23. Walker EA, Katon WJ, Hansom J, Harrop-Griffiths J, Holm L, Jones ML et al. Psychiatric diagnoses and sexual victimization in women with chronic pelvic pain. Psychosomatics 1995;36:531-540.

24. Nijenhuis ERS, Van Dyck R, ter Kuile MM, Mourits MJE, Spinhoven P, Van der Hart O. Evidence for associations among somatoform dissociation, psychological dissociation and reported trauma in patients with chronic pelvic pain. Journal of Psychosomatic Obstetrics and Gynecology 2003;24:87-98. 
25. Fry RPW, Crisp AH, Beard RW, McGuigan S. Psychosocial aspects of chronic pelvic pain, with special reference to sexual abuse. Postgraduate Medical Journal 1993; 69:566-574.

26. Finkelhor D, Associates. A sourcebook on child sexual abuse. Beverly Hills: Sage, 1986.

27. Walker EA, Katon WJ, Neraas K, Jemelka RP, Massoth D. Dissociation in women with chronic pelvic pain. American Journal of Psychiatry 1992;149:534-537.

28. Tillman JG, Nash MR, Lerner PM. Does trauma cause dissociative pathology? In Lynn SJ, Rhue JW, editors. Dissociation: Clinical and theoretical perspectives. New York: Guilford, 1994:395-415.

29. Van IJzendoorn MH, Schuengel C. The measurement of dissociation in normal and clinical populations. Meta-analytic validation of the Dissociative Experiences Scale (DES). Clinical Psychology Review 1996;16:365-382.

30. Mulder RT, Beautrais AL, Joyce PR, Fergusson DM. Relationship between dissociation, childhood sexual abuse, childhood physical abuse, and mental illness in a general population sample. American Journal of Psychiatry 1998;155:806-811.

31. Bernstein EM, Putnam FW. Development, reliability and validity of a dissociation scale. Journal of Nervous and Mental Disease 1986;174:727-735.

32. Waller NG, Putnam FW, Carlson EB. Types of dissociation and dissociative types: A taxometric analysis of dissociative experiences. Psychological Methods 1996; 1:300-321.

33. Vanderlinden J, Van Dyck R, Vandereycken W, Vertommen H, Verkes RJ. The Dissociation Questionnaire: Development and characteristics of a new self-reporting questionnaire. Clinical Psychology and Psychotherapy 1993;1:21-27.

34. Nijenhuis ERS, Spinhoven P, Van Dyck R, Van der Hart O, Vanderlinden J. The development and psychometric characteristics of the Somatoform Dissociation Questionnaire (SDQ-20). Journal of Nervous and Mental Disease 1996; 184:688-694.

35. Nijenhuis ERS, Spinhoven P, Van Dyck R, Van der Hart O, Vanderlinden J. Psychometric characteristics of the Somatoform Dissociation Questionnaire: A replication study. Psychotherapy and Psychosomatics 1998;67:17-23.

36. Draijer N, Langeland W. Childhood trauma and perceived parental dysfunction in the etiology of dissociative symptoms in psychiatric inpatients. American Journal of Psychiatry 1999;156:379-385.

37. Nijenhuis ERS, Van der Hart O, Kruger K. The psychometric characteristics of the Traumatic Experiences Checklist (TEC): First findings among psychiatric outpatients. Clinical Psychology and Psychotherapy 2002;9:200-210.

38. Vanderlinden J. Dissociative experiences, trauma and hypnosis: Research findings and clinical applications in eating disorders. Delft: Eburon, 1993.

39. Derogatis LR. SCL-90. Administration, scoring and procedures manual 1 for the $R$ (evised) version and other instruments of the psychopathology rating scale series. Baltimore, MD: Clinical Psychometrics Research Unit, Johns Hopkins University School of Medicine, 1998.

40. Arrindell WA, Ettema JHM. SCL-90. Een multidimensionele psychopathologie indicator. Lisse: Swets \& Zeitlinger, 1986.

41. Zigmond AS, Snaith RP. The Hospital Anxiety and Depression Scale. Acta Psychiatrica Scandinavica 1983;67:3-9. 
42. Spinhoven P, Ormel J, Sloekers PP, Kempen GI, Speckens AE, Van Hemert AM. A validation study of the Hospital Anxiety and Depression Scale (HADS) in different groups of Dutch subjects. Psychological Medicine 1998;27:363-370.

43. Nijenhuis ERS, Van Dyck R, Spinhoven P, Van der Hart O, Chatrou M, Vanderlinden $\mathrm{J}$ et al. Somatofom dissociation discriminates among diagnostic categories over and above general psychopathology. Australian and New Zealand Journal of Psychiatry 1999;33:511-520

44. Romans S, Belaise C, Martin J, Morris E, Raffi A. Childhood abuse and later medical disorders in women. An epidemiological study. Psychotherapy and Psychosomatics 2002; $71: 141-150$.

45. Schacter DL. The recovered memories debate. In Conway MA, editor. Recovered memories and false memories. Oxford: Oxford University Press, 1997:63-99.

46. Draijer N, Langeland W. Childhood trauma and perceived parental dysfunction in the etiology of dissociative symptoms in psychiatric inpatients. American Journal of Psychiatry 1999;156:379-385.

47. Cardena E, Spiegel D. Dissociative reactions to the San Francisco Bay Area earthquake of 1989. American Journal of Psychiatry 1993;150:474-478.

48. Engel CE, Walker EA, Katon WJ. Factors related to dissociation among patients with gastrointestinal complaints. Journal of Psychosomatic Research 1996;40:643-653.

Direct reprint requests to:

Prof. Dr. Ph. Spinhoven

Faculty of Social and Behavioral Sciences

Section of Clinical and Health Psychology

P.O. Box 955

2300 RB Leiden

The Netherlands

e-mail: Spinhoven@fsw.leidenuniv.nl 